\title{
CLOSED LOOP CONTROL OF MULTI LEVEL INVERTER USING REVERSE VOLTAGE TOPOLOGY
}

\author{
Archana P \\ Assistant Professor, EEE Department, NSS College of Engineering, Palakkad, India
}

\begin{abstract}
In this paper a new topology with a reversing voltage component is proposed which will improve the multilevel performance by compensating the disadvantages of increased number of components, complex pulse width modulation control method and voltage balancing problem. This topology requires fewer components compared to existing inverter topologies (particularly in higher levels) and requires fewer carrier signals and gate drives. Therefore the overall cost and complexity are greatly reduced particularly for higher output voltage levels. This paper describes the general multilevel inverter schematic and modified circuit having only seven switches for seven- level multilevel inverter using reverse voltage topology. A general method of multilevel modulation phase disposition (PD) SPWM is utilized to drive the inverter and can be extended to any number of voltage levels. The simulation of a modified seven level multilevel inverter using reverse voltage topology is also presented here.
\end{abstract}

Keywords: Multi -level inverter, Phase Disposition, Power electronics, PWM, Reverse voltage, SPWM, Topology.

Cite this Article: Archana P, International Journal of Electrical Engineering \& Technology, 10(2), 2019, pp. 108-114. http://iaeme.com/Home/issue/IJEET?Volume $=10 \&$ Issue $=2$

\section{INTRODUCTION}

MLI's are used for high power and high voltage applications. MLI's have unique structure which makes it possible to reach high voltages with less harmonic content. Inverter is a device which converts dc power to ac power. Two level inverters require high switching frequency and disadvantages are less efficiency, high cost and high switching losses. Various PWM strategies are require to get high quality output which leads to high switching losses. MLI's are introduced to overcome these problems. MLI is able to synthesize output voltages with reduced harmonic distortion and lower electromagnetic interference. The advantages of MLI are improvement in staircase waveform quality, less input current distortion, lower electromagnetic interference. MLI's are used in drives, PV systems and automotive applications. The harmonic content of the output voltage waveform decreases as the number of output voltage increases.

MLI's are mainly classified as cascaded MLI, diode clamped MLI, flying capacitor MLI. The control method of cascaded H- bridge MLI because it doesn't have any clamping diode 
and flying capacitor. Cascaded MLI reaches higher reliability and this is used for large automotive electric drives. The main disadvantage is the increase in number of power switches that normally contributes to the complexity in controlling power switches. Many methods have been developed to decrease the number of switches. Modulation strategies applied to MLI's are selective harmonics elimination, carrier based PWM, space vector modulation, and fundamental frequency modulation. The PWM control is the most efficient method of controlling output voltage within the inverters. The carrier based PWM schemes used for MLI's is much more efficient, realized by the intersection of modulating signal with triangular carrier waveform. This paper is based on seven level inverter with reverse voltage topology which requires less number of switches than conventional topologies. This paper aims at generation of carrier based PWM scheme using PD method and can control output voltage and frequency and reduce the harmonic components in load currents. Here PD SPWM use ((n-1)/2) carriers to drive the inverter. In PD, all the carrier waveforms are in phase.

\section{MULTILEVEL INVERTER USING REVERSE VOLTAGE TOPOLOGY}

Conventional cascaded MLI's require large number of switches and the power semiconductor switches are combined to produce an output in positive and negative polarity. In the new topology, there is no need to utilize all the switches in high frequency. This topology seperates output voltage into level generation and polarity generation parts. Level generation part generates levels in positive polarity and polarity generation part generates the polarity of the output voltage. Level generation part needs high frequency switches and polarity generation part requires low frequency switches operating at line frequency.

Fig. 1 shows schematic diagram of a single phase seven- level reverse voltage topology. This MLI's can be increased to higher voltage levels by increasing middle section. This topology requires less switches and it can be applied to three phase application. The PD SPWM for proposed topology needs only half the number of conventional carriers for SPWM. PD SPWM for seven level conventional inverters requires six carriers, but in the proposed system only three carriers are needed.

MLI control with less number of carriers is the main advantage in this topology. Separate dc sources are needed for this topologyThe proposed MLI has better efficiency than conventional MLI.

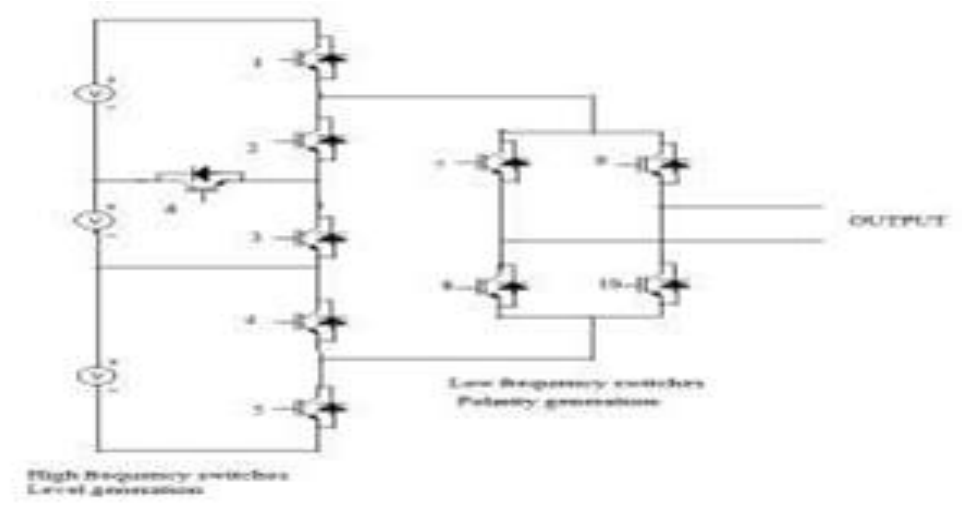

Figure 1 General single phase multilevel inverter (using reverse voltage topology) circuit

In seven level inverters, ten switches and three dc sources are used. The left portion of the circuit in Fig. 1 generates the required output levels and the right portion of the circuit generates the polarity of the output voltage. The right portion of the circuit is called polarity 
generation part, it reverses the output of the level generation part, when the voltage polarity requires to be changed for negative polarity. MLI control is implemented using reduced number of carriers, which is a great achievement. Proposed topology does not need fast switches for the polarity generation part. The proposed MLI has better efficiency. The switching modes are selected such that to reduce the switching transitions for avoiding the unwanted voltage levels. This will minimize the switching power dissipation. There are six possible switching patterns to control the multilevel inverter (see Table 1). The sequence of switches (2-3-4), (2-3-5), (2-6-5) and (1-5) are used for levels 0, 1, 2 and 3 respectively. The output voltage is the sum of voltage sources, which are included in the current path.

Table 1 Switching Modes

\begin{tabular}{|c|c|c|c|c|}
\hline LEVEL & 0 & $\mathrm{~V}_{\mathrm{dc}}$ & $2 \mathrm{~V}_{\mathrm{dc}}$ & $3 \mathrm{~V}_{\mathrm{dc}}$ \\
\cline { 1 - 2 } MODE & & & & \\
\hline 1 & $2,3,4$ & $2,3,5$ & 1,4 & 1,5 \\
\hline 2 & & $2,4,6$ & $2,6,5$ & \\
\hline
\end{tabular}

\section{PROPOSED CIRCUIT USING REVERSE VOLTAGE TOPOLOGY}

Reduced number of switches leads to reduced cost and complexity. This also leads to reduced losses and increased efficiency. This circuit requires only seven switches.

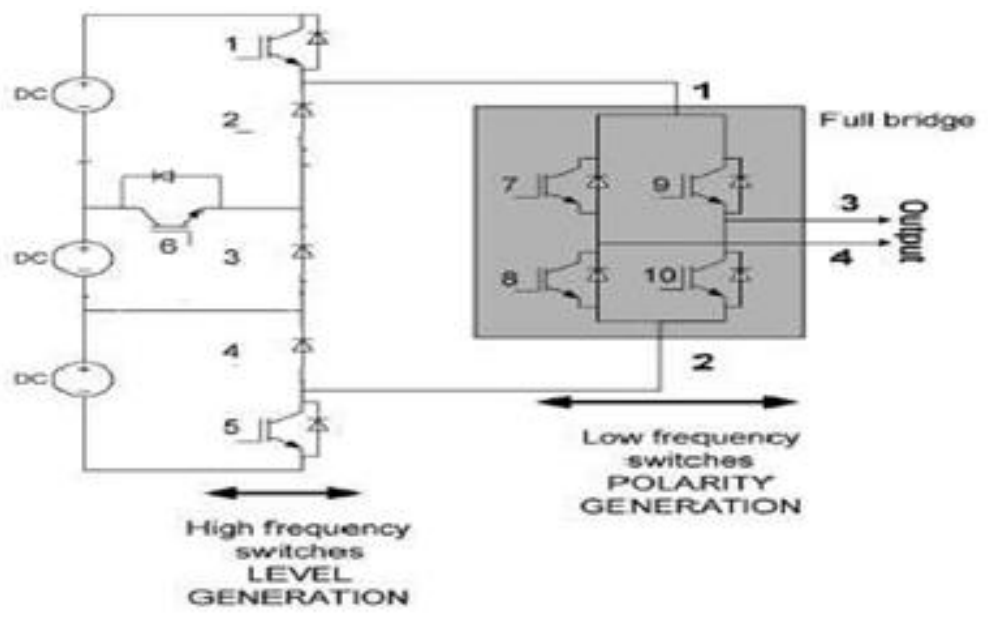

Figure 2 Proposed circuit using RV topology

Here high frequency switches 2, 3 and 4 in the general single phase multilevel inverter shown in Fig. 1 are replaced by diodes 2, 3 and

Fig. 2 shows the proposed circuit using reverse voltage topology. Figure .3 shows general block diagram of seven-level proposed topology. 


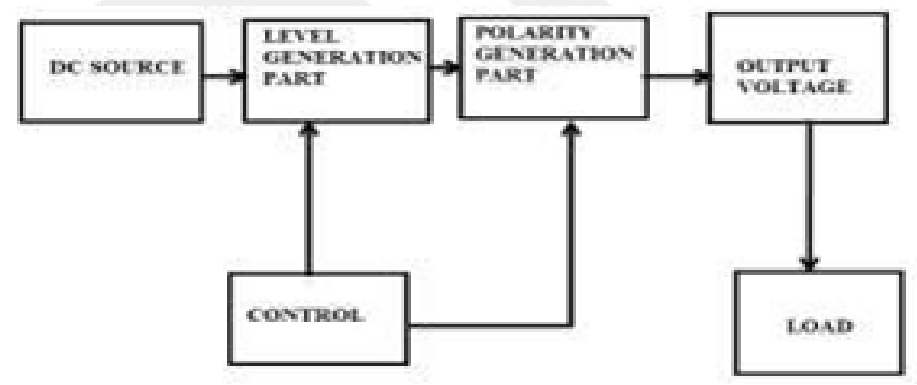

Figure 3 General Block Diagram of Seven Level proposed Topology

\section{MODES OF OPERATION}

Fig. 4 shows the level $0=0 \mathrm{~V}_{\mathrm{dc}}$ of seven level inverter. Here the diodes $(2,3,4)$ are conducting to develop zero voltage. These switches are driven by PD-SPWM.

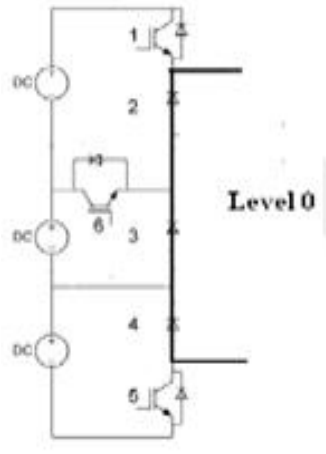

Figure 4. Level $0=0 \mathrm{~V}_{\mathrm{dc}}$

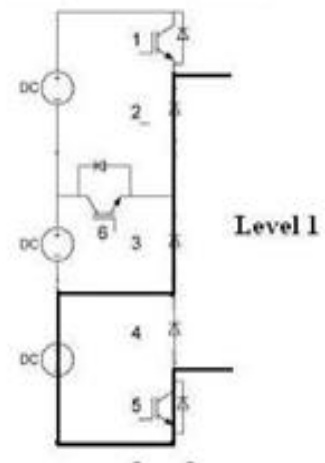

Figure 5. Level $1=\mathrm{V}_{\mathrm{dc}}$

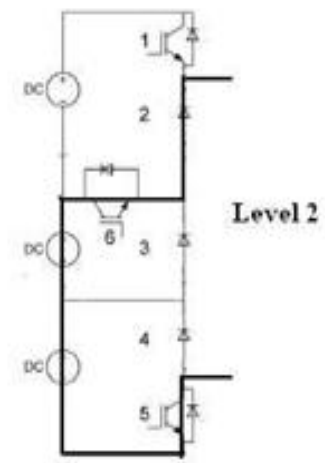

Figure 6. Level $2=2 \mathrm{~V}_{\mathrm{dc}}$

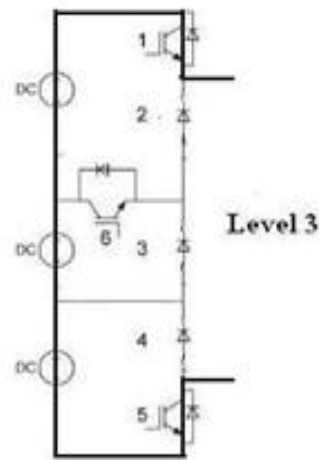

Figure 7. Level $3=3 \mathrm{~V}_{\mathrm{dc}}$

\section{CONTROL STRATEGY}

The carrier based PWM technique fulfills the on and off states of the switches by comparing a modulating signal $\mathrm{V}_{\mathrm{A}}$ (desired ACnoutput voltage and a triangular waveform $\mathrm{V}_{\mathrm{C}}$ (carrier signal). The modulating signal $\mathrm{V}_{\mathrm{A}}$ is a sinusoidal signal at frequency $\mathrm{F}_{\mathrm{C}}$ and amplitude $\mathrm{V}_{\mathrm{A}}$ and the triangular signal $V_{C}$ is at frequency $F_{C}$ and amplitude $V_{C}$. This is the SPWM method. Th modulation index is defined as $\mathrm{m}_{\mathrm{a}}=\mathrm{V}_{\mathrm{C}} / \mathrm{V}_{\mathrm{A}}$ and the normalized carrier frequency is $\mathrm{m}_{\mathrm{f}}=$ $\mathrm{F}_{\mathrm{C}} / \mathrm{F}_{\mathrm{A}}$. PWM has the following advantages.

- The entire control circuit is digital, digital control lines reduce the susceptibility to interference and also motors may be able to operate at lower speeds.

- The output voltage control can be obtained without any additional components.

- Lower order harmonics can be reduced along with its output voltage control.

In this topology, PD-SPWM is adopted for its simplicity and the carriers are in phase with each other. Here PD-SPWM is used for driving the high frequency switches and low frequency polarity generation part drive signals are generated with the line frequency $(50 \mathrm{~Hz})$ and they only changes at zero- voltage crossings. For a conventional cascaded MLI, (n-1) triangle waveforms are used. In the proposed topology, a phase modulation signal is compared with (n-1)/2 triangle waveforms for an n-level inverter.

One of the main advantages of this topology is that it requires less high frequency switches and the reliability of the system is indirectly proportional to the number of its components. As the number of high frequency switches is decreased, the reliability of the converter is increased. Hence the reliability is highly improved in this topology. Also high 
frequency switches are expensive and easily damaged. It can clearly be mentioned that the number of components of this topology is lower than that of other topologies and it will decrease tremendously with higher voltage levels. Switches in the full bridge converter are switched at line frequency.

\section{SIMULATION RESULTS}

Simulation of proposed MLI is performed using MATLAB. The output waveforms of proposed multilevel inverter are given. All input DC sources are equal. MATLAB 7.10.0 (R2010a) is used for simulation part of the project. Simulation of the proposed topology of MLI is performed using MATLAB. Simulation results for the proposed system are given below. Modulation techniques are used in multilevel inverter to synthesis a controlled output voltage. There are various modulation techniques, of which phase disposition pulse width modulation is used here. Here phase disposition SPWM id used for driving the switches in the level generation part and switches in the polarity generation part are driven by the line frequency. In this proposed topology, a phase modulation signal is compared with (n-1)/2 carriers for an n-level inverter and all the carriers are in phase. Since this converter works only in positive polarity, this topology requires half of the conventional carriers for SPWM controller. Here DC power supplies are adjusted to $50 \mathrm{~V}$ and switching frequency is $4 \mathrm{KHz}$. Output voltage is $300 \mathrm{~V}_{\mathrm{p} \text {-p. }}$. In this proposed topology, a phase modulation signal is compared with (n-1)/2 carriers for an n-level inverter and all the carriers are in phase. The waveform of proposed MLI with an inductive load is shown in Fig. 8.

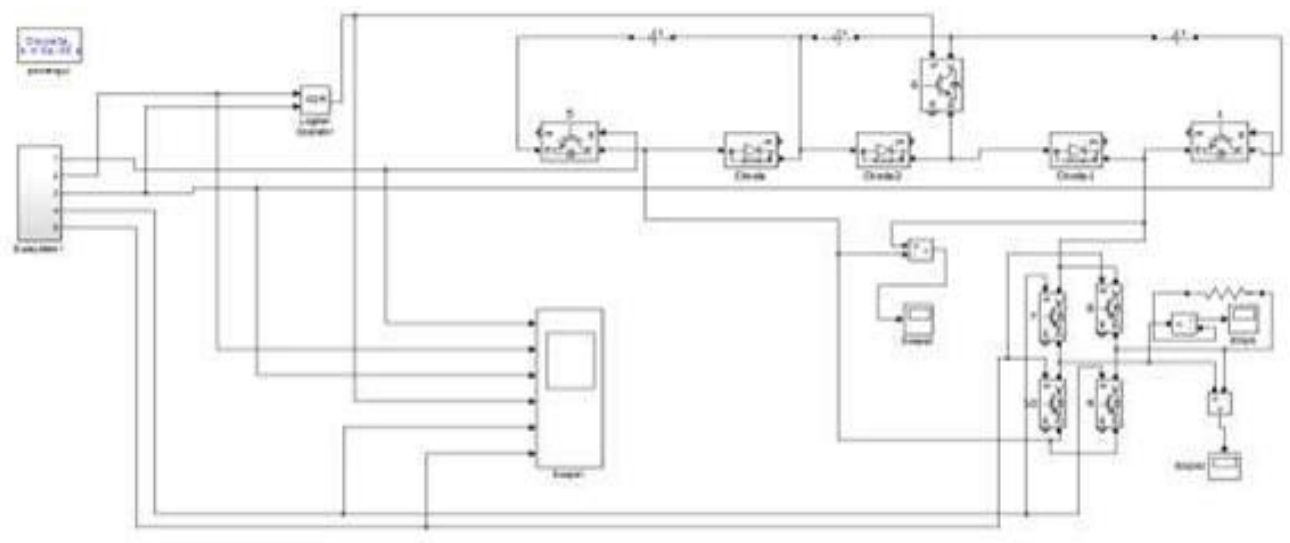

Figure 8. Simulation diagram of proposed system

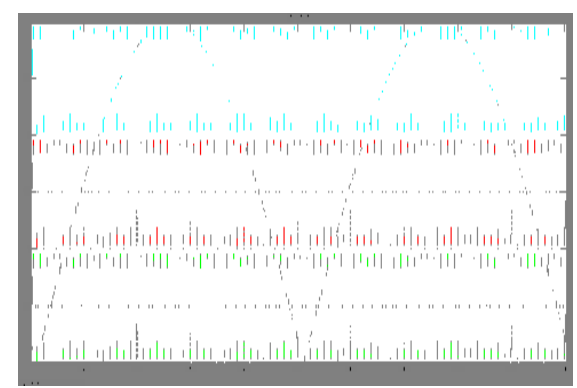

Figure 9. SPWM carrier and modulator

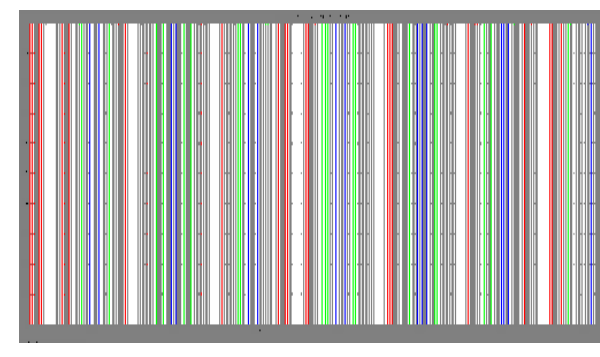

Figure 10. Gate signals for SPWM 


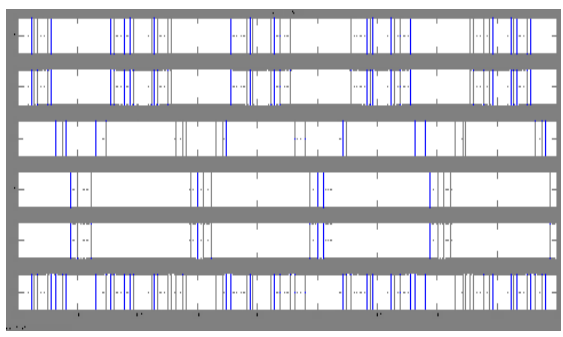

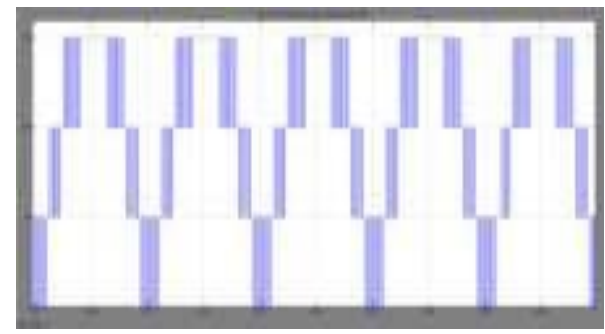

Figure 11. Complete gate signals for seven-level generation Figure 12. Output voltage of level generation part

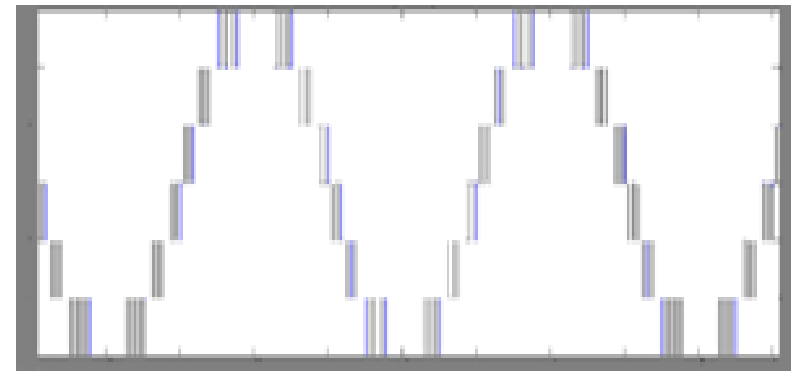

Figure 13 Output voltage of polarity generation part

\section{CONCLUSIONS}

MLI's have been used in many industrial applications like HVDC, FACTS, EV, PV systems, UPS, and industrial drive applications. In ths proposed topology, switching operations are separated into high and low frequency parts. Instead of using cascaded inverter topology, proposed topology is better for all these applications because it has less control complexities, cost is also less and gives less \% THD. Thus proposed topology is preferred than conventional cascaded inverter.

The PD-SPWM control method is used to drive the inverter. The PWM for this topology has fewer complexities since it only generates positive carriers for PWM control. This topology can effectively work as a multilevel inverter with a reduced number of carriers for PWM

\section{REFERENCES}

[1] L. M. Tolbert, F. Z. Peng, and T. G. Habetler, -Multilevel Converters for Large Electric Drives,\|IEEE Trans.Ind.Appl., vol.35, no.1, pp.36-44, Jan./Feb.1999.

[2] R.H.Osman, AMedium-Voltage Drive Utilizing Series-Cell Multilevel Topology for Outstanding Power Quality,„Conf.Rec.34th IEEE IASAnnu. Meeting, 1999, vol.4, pp.2662-2669.

[3] R. Teodorescu, F. Blaabjerg, J. K. Pedersen, E. Cengelci, and P. N. Enjeti, -Multilevel Inverter by Cascading Industrial VSI,\|

[4] IEEE Trans.Ind.Electron., vol.49, no.4, pp.832-838, Aug.2002.

[5] G. J. Su, -Multilevel DC-Link Inverter,॥ IEEE Trans.Ind.Appl., vol.41, no.3, pp.848854, May/Jun.2005. G. Ceglia, V. Guzman,

[6] C. Sanchez, F. Ibanez, J. Walter, and M. I. Gimenez, -A New Simplified Multilevel Inverter Topology for Dc-Ac Conversion,॥ 
[7] IEEE Trans. Power Electron., vol.21, no.5, pp.1311-1319, Sep.2006.

[8] G. Ceglia, V. Guzman, C. Sanchez, F. Ibanez, J. Walter, and M. I. Gimenez, -A New Simplified Multilevel Inverter Topology for Dc-Ac Conversion,„ IEEE Trans. Power Electron., vol.21, no.5, pp.1311-1319, Sep.2006.

[9] X. Yun, Y. Zou, X. Liu, and Y. He, -A Novel Composite Cascade Multilevel Converter,|Proc.33rd IEEE IECON, 2007, pp.1799-1804.

[10] S. A. Gonzalez, M. I. Valla, and C. F. Christiansen, -Analysis of a Cascade Asymmetric Topology for Multilevel Converters, „Proc.IEEE ISIE, 2007,pp.1027-1032.

[11] T. L. Skvarenina, The Power Electronics Handbook. Boca Raton, FL: CRC Press, 2002.

[12] E. Babaei, -Optimal topologies for cascaded sub-multilevel converters, $\|$ J. Power Electron., vol. 10, no. 3, pp. 251-261, May 2010.

[13] P. Lezana and J. Rodriguez, - Mixed multicell cascaded multilevel inverter, in Proc. IEEE ISIE, 2007, pp. 509-514.

[14] A. Radan, A. H. Shahirinia, and M. Falahi, -Evaluation of carrier-based PWM methods for multi-level inverters, in Proc. IEEE ISIE, 2007, pp. 389-394.

[15] J.-S. Lai and F. Z. Peng, - Multilevel converters-a new breed of power converters,॥ IEEE Trans. Ind. Appl., vol. 32, no. 3, pp. 509-517, May/Jun. 1996 